\title{
Advanced simulation methods for heat pump systems
}

\author{
Kristian Huchtemann Dirk Müller \\ Institute for Energy Efficient Buildings and Indoor Climate \\ E.ON Energy Research Center, RWTH Aachen University \\ Jägerstraße 17/19, 52066 Aachen, Germany \\ khuchtemann@eonerc.rwth-aachen.de
}

\begin{abstract}
Within the use of renewable energies in buildings several dynamic influences and interactions have to be regarded. For example, the performance of heat pump systems depends sensitively on weather or geological effects as well as on building and user behaviour. An energetic optimization requires an intelligent coupling and control of all components of the building services installation, the building envelope and the influences mentioned.

The Modelica libraries developed at the Institute for Energy Efficient Buildings and Indoor Climate allow a detailed analysis of the overall system including the various influences and interactions.

Keywords: building simulation; heat pump; building services installation
\end{abstract}

\section{Introduction}

The building sector is getting more and more into the spotlight of energy efficiency programs considering its great portion to the overall energy consumption and its huge potential for energy savings. As every existing and new building is a unique system, adaptable simulation tools are required to calculate and predict its energy demand.

For example heat pumps offer a huge potential of energy savings compared to classic heating devices in buildings. Possible savings depend on the performance of the heat pump, which is described through the Seasonal Performance Factor $\beta$ :

$$
\beta=\frac{Q_{u s e}}{W_{e l}}
$$

$Q_{u s e}$ is the generated heat during one year and $W_{e l}$ is the electrical energy demand of the compressor and the auxiliary drives [1]. In practice, identical heat pump types often achieve very different performance factors. The reasons for that are generally known - the control system and the ground source heat exchanger have a significant impact on the system. For example, heat source temperatures or needed supply temperatures of the heating system influence the performance. Thus an analysis of the heat pump performance requires an analysis not of the heat pump alone but of the overall system. A sample scheme in figure 1 shows the most important components of heat pump systems.

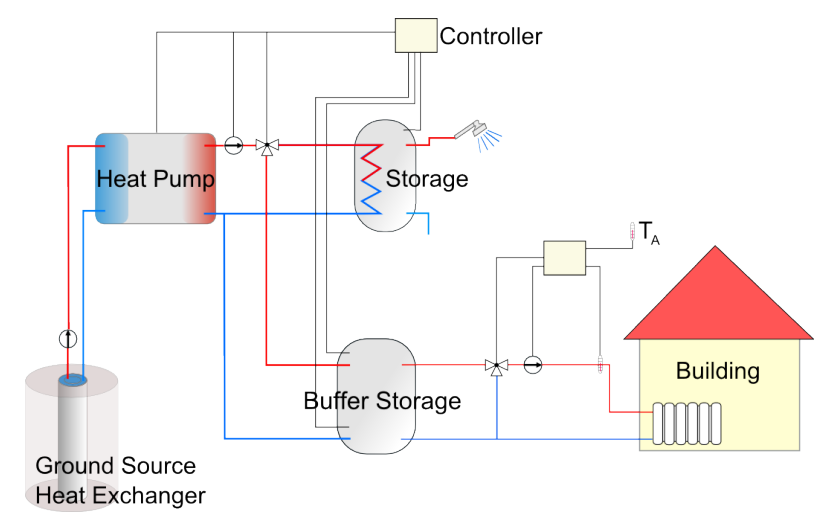

Figure 1: Sample scheme of a heat pump system.

The Modelica libraries developed at the Institute for Energy Efficient Buildings and Indoor Climate allow a detailed modelling of the whole thermo-hydraulic system including the heat source, heat pump, water storages and heat sink - the building. User behaviours are being implemented as well as weather data, control and geologic models. In this way, all relevant influences on the heat pump performance are regarded, sensitivity analyses are accomplished and control strategies are examined. 


\section{Building Library}

The building models represent structural effects and user influences [2]. They are compatible with the building services installation models described below. The library contains multilayer walls, windows and doors including the phenomena involved such as heat conduction, convection and radiation. A room model is shown in figure 2. The air volume of the room is calculated by the medium models of the Modelica.Media library. User influences are described by internal heat loads and variable air exchange. The library includes an extensive weather model based on test reference year data of the German Meteorological Service, offering boundary conditions for the simulation. The model calculates the ambient temperature, air pressure, humidity and solar exposure rates on arbitrarily sighted surfaces.

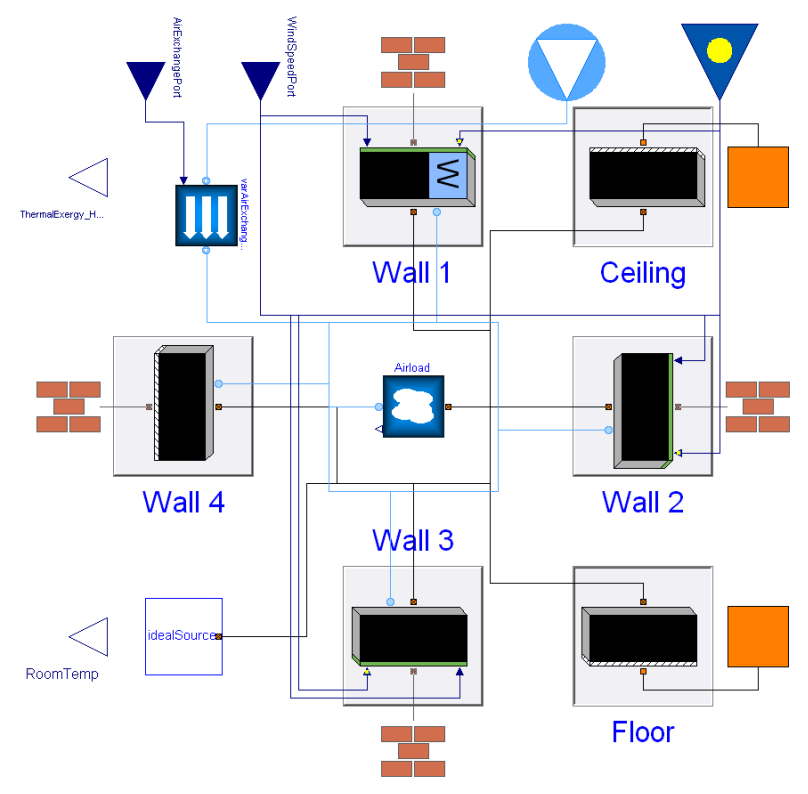

Figure 2: Model of a sample room.

\section{Building Services Installation Li- brary}

The building services installation library contains basic components of building services installations, such as pumps, pipes, boilers, heaters and valves. It uses medium models of the Modelica.Media and components of the Modelica_Fluid libraries. Simple components calculate state changes of fluid by look-up tables, more complex models use finite volume methods and empiric correlations [2]. Pipes, heat exchangers and thermally activated building parts are implemented in the latter way. Figure 3 shows a simple heating circuit containing some models of the library.

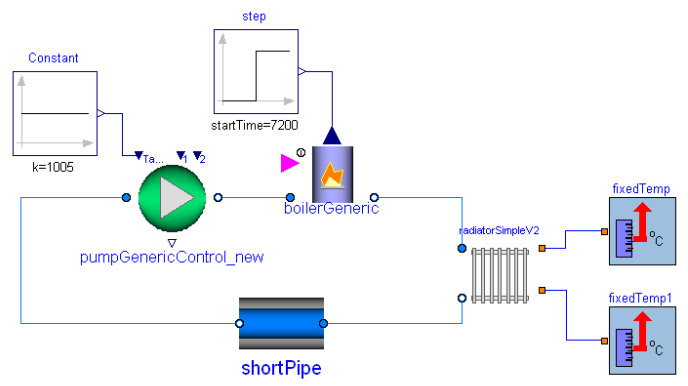

Figure 3: Model of a simple heating circuit.

\section{Heat Pump System Library}

For the purpose of modeling heat pump systems, the existing libraries are complemented by a new library. It includes different heat pump models, storage models, ground source heat exchangers and ground models as well as controllers.

\subsection{Heat Pump Model}

The heat pump model is implemented as a black box model consisting of two heat exchangers that are connected to a module that calculates the heat flows and compressor power by look-up tables using manufacturer data. Generally this data is given at working points standardised by [3]. The more working points are given the better the real heat pump's dynamic behaviour is reproduced. The basic working scheme of this black-box model is shown in figure 4 .

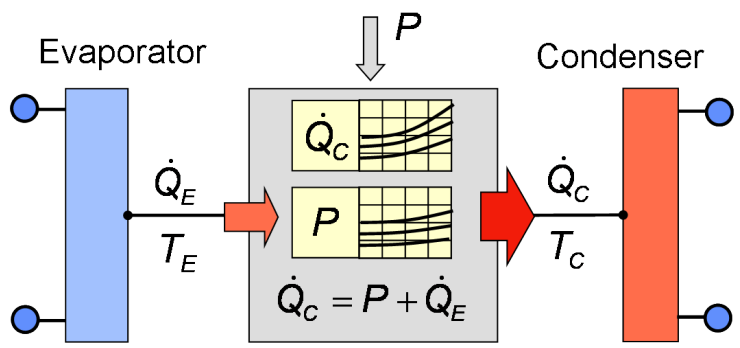

Figure 4: Scheme of the table based heat pump model.

A more detailed model implementing the refrigerant circuit is being developed using external fluid properties by the ExternalMedia library [4]. 


\subsection{Ground Source Heat Exchanger Model}

Ground source heat exchangers serve as heat source for the heat pump system. They are using either the upper ground's or the relatively deep ground's (up to $200 \mathrm{~m}$ depth) heat capacity.

The models describe coaxial pipes as well as $\mathrm{u}$ formed pipes discretised in axial direction connected to a ground model. The ground model is an axially and radially discretised volume enclosing the borehole. At the borders of the simulated ground volume a boundary condition is assumed. In figure 5 a coaxial pipe is modeled and a constant temperature is assumed as boundary condition in a certain radius to the borehole. The pipe model can also be initialised with an increasing temperature representing the geothermal coefficient. The boundary condition is then adapted accordingly.

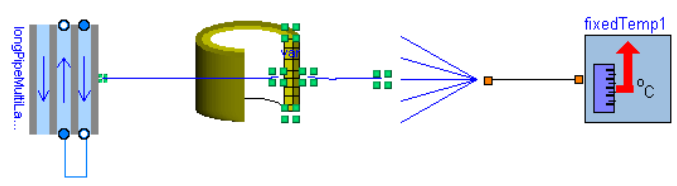

Figure 5: Model of a coaxial pipe connected to a ground model with constant temperature boundary condition.

The simulation of such a model with a given heat extraction time series taken from field test data leads to a funnel-shaped distribution of temperature in the surrounding ground (see figure 6). Ground-water flow can strongly influence such distributions of temperature. That is why more complex ground models are being developed following the example of the software SHEMAT [5].

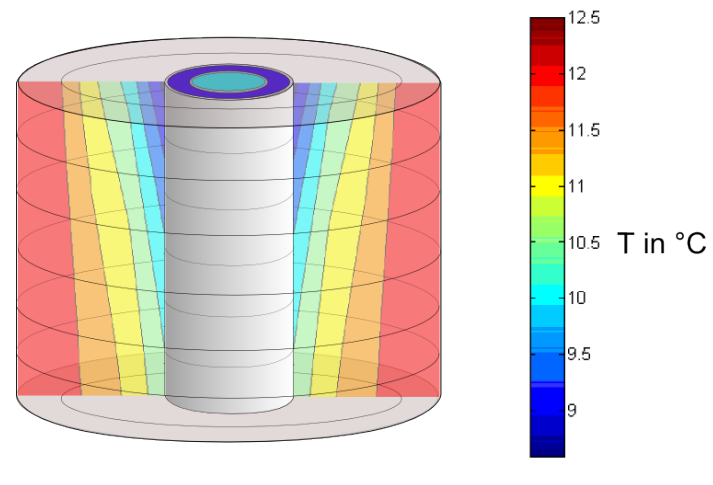

Figure 6: Simulation results: Temperature field in the profile of the ground model.

\subsection{Stratified Storage Model}

Storages are important components of the heat pump system. They are used to handle variable heating demand or serve as drinking water storages. A wide range of different storage types exist, such as storages with heat exchangers, combined buffer and drinking water storages as well as stratified water storages. Basically, every storage has to be modeled separately.

However, a unified modeling can be done for simple buffer storages, that generally consist of a fluid volume with several fluid inlets and outlets. To implement stratification inside this volume, the buffer storage model consists of several fluid volumes representing fluid layers (see figure 7).

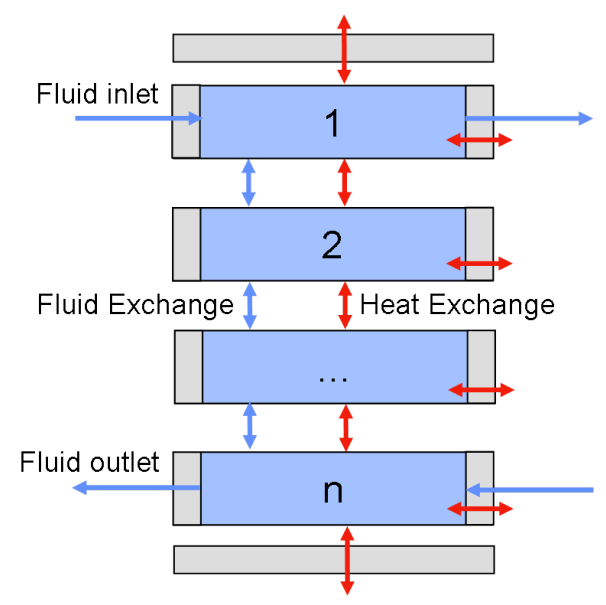

Figure 7: Model of the stratified buffer storage.

The layers are connected to each other allowing heat and fluid flow. Buoyancy effects are regarded by an effective heat conductance $\lambda_{\text {eff }}$ depending on the temperature differences between the layers:

$$
\begin{array}{r}
\lambda_{\text {eff }}=\lambda_{\text {water }} \text { if } T_{n}>T_{n+1} \\
\lambda_{\text {eff }}=\lambda_{\text {water }}+\lambda_{\text {turbulent }} \text { if } T_{n} \leq T_{n+1}
\end{array}
$$

The turbulent heat conductance is a function of the layer thickness, its temperature and the temperature difference to the above layer and is based on the work of Viskanta et al. [6]. The buffer storage model has fluid inlets and outlets in the top and bottom layers. The quality of stratification in the specific storage can be fitted by choosing the number of layers in the model.

\subsection{Validation of Models}

A validation of library components is done using the data from a field study in Germany recorded by 
the Fraunhofer Institute for Solar Energy Systems in Freiburg, which was initiated by the E.ON Energie AG. The field study is recording time series of temperature and volume flows at several points of the regarded heat pump systems. This data is taken as input to the components or combined components. This way the model's reaction can be compared to the behaviour of the real component.

This is done for the table-based heat pump model in the set-up shown in figure 8. Figure 9 shows the results for two different heat pump types, that means two different data sets. The error gets up to $10 \%$ in few models under certain circumstances, but generally the heat pump behaviour can be simulated well by the manufacturers' data.

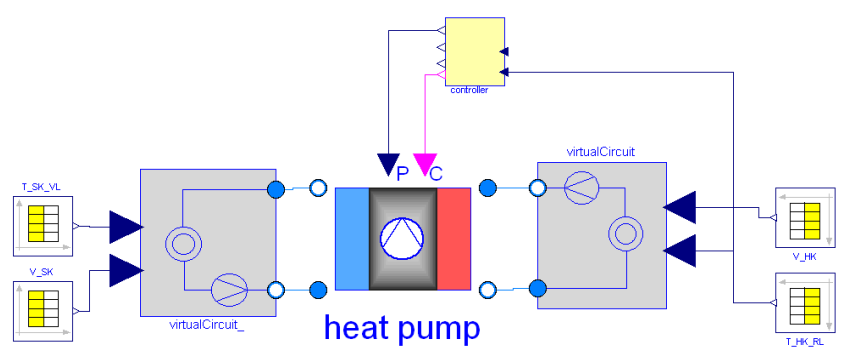

Figure 8: Validation of the heat pump model.
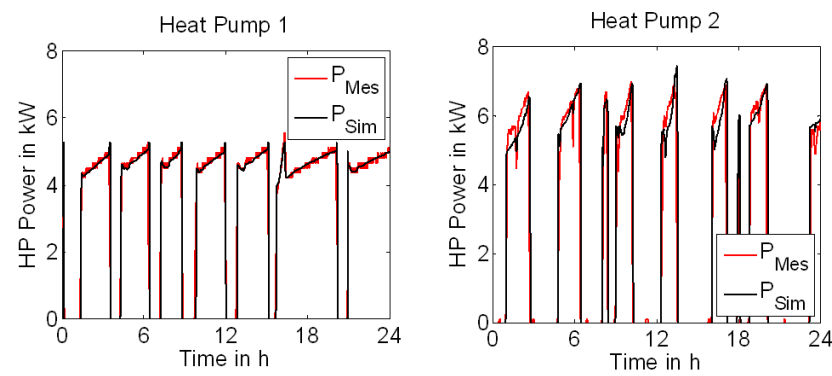

Figure 9: Comparison of simulated heat pump power to field test data.

Other components are validated analogously. For the validation of ground source heat exchanger models the field test data is complemented by thermal response test data.

\section{Combined Simulation}

As mentioned in the beginning, the combined simulation of the thermal building behaviour, the hydraulic components, weather- and user influences and, in case of geothermal heat pumps, geothermal heat exchangers and ground models is required to describe the main influences on the performance of the heating system. Figure 10 shows a model according to the sample heat pump system in figure 1.

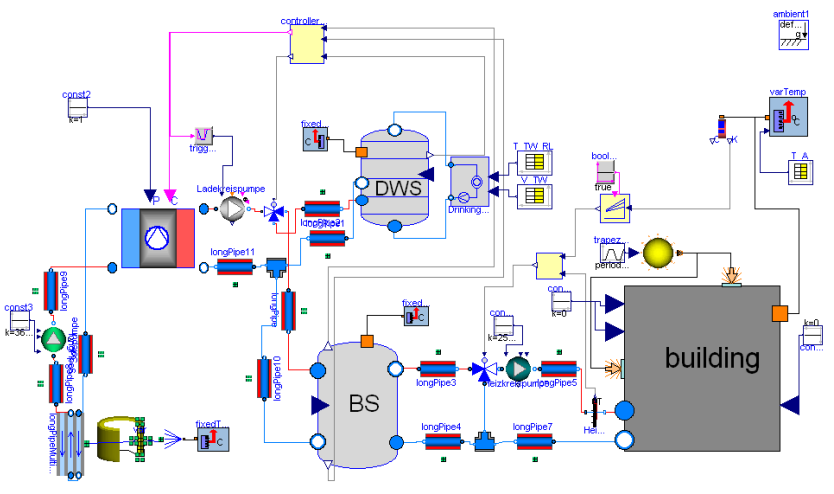

Figure 10: Model of the total system.

The simulation results of different temperatures occurring in the system are displayed in figure 11. The ambient temperature $\left(T_{A}\right)$ is a given time series from field test data. At ambient temperatures above $15{ }^{\circ} \mathrm{C}$ the heating is turned off by the controller, so that the buffer storage is not discharged. During that time the top and bottom buffer storage temperatures $\left(T_{B S, t}\right.$ and $\left.T_{B S, b}\right)$ decline because of storage heat losses. The reaction of the evaporator and condenser temperature on the water side $\left(T_{E}\right.$ and $\left.T_{C}\right)$ are shown, too. The highest peaks of the condenser temperature occur when the drinking water storage is charged. The brine temperatures $\left(T_{\text {Flow }}\right.$ and $T_{\text {Return }}$ ) show an effect of short term rebound of ground temperature during the turn-off interval of the heat pump. A room temperature $\left(T_{R}\right)$ of $20{ }^{\circ} \mathrm{C}$ can be ensured throughout the whole day.
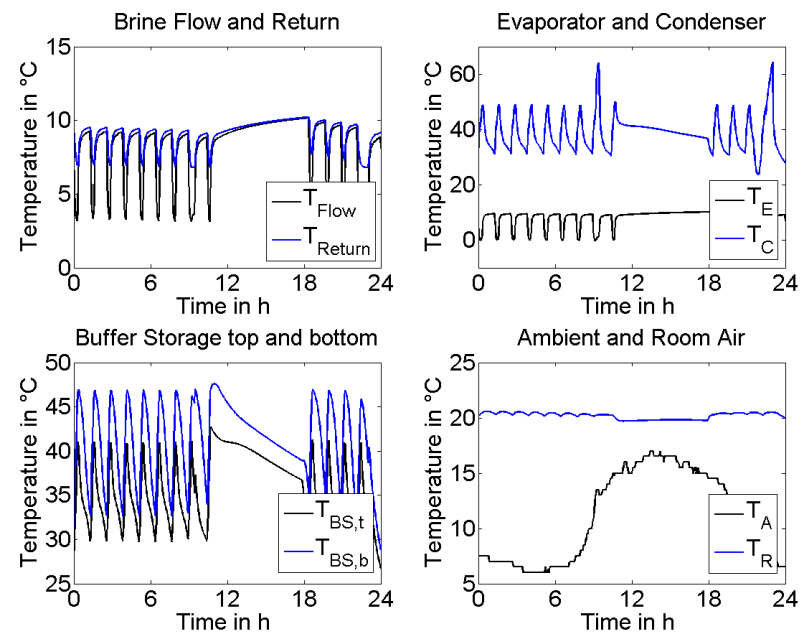

Figure 11: Simulation results of different temperatures of the total system. 


\section{Analyses of the heat pump system}

A sensitivity analysis is done, varying the volume of the buffer storage. Results are shown in figure 12. The heat pump power is displayed for the time of 24 hours each for a January and April day using a small and a big buffer storage. Small volumes mean smaller heat losses but also a high number of operating intervals. This has to be avoided to ensure the heat pump's lifetime.
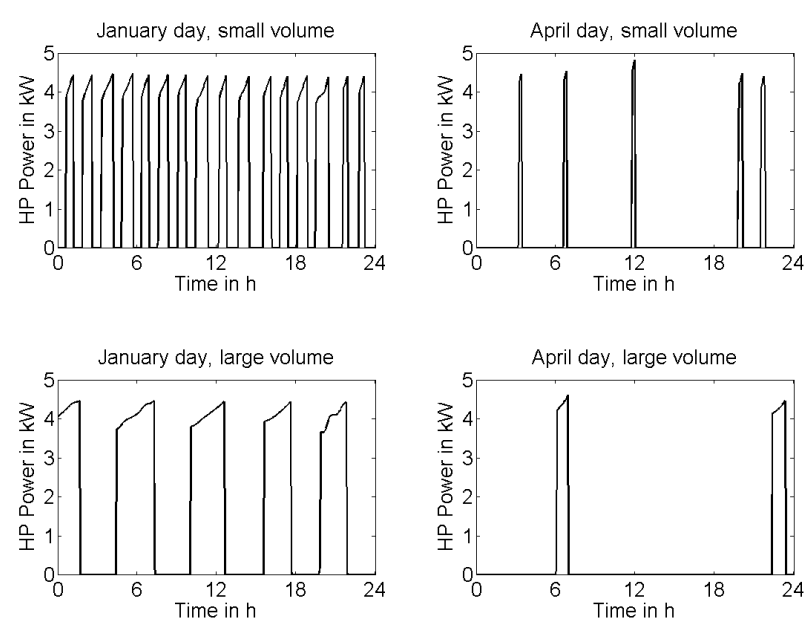

Figure 12: Simulation results: Heat Pump electric power.

For a January day with a high and constant heating demand a small buffer storage cannot ensure the temperatures required by the heating system. The temperature in the buffer storage gets low faster than the heat pump is allowed to turn on again by the controlling system. Minimum turn-off intervals are implemented in the controls. With a large buffer storage the required supply temperatures can be ensured and a reduced amount of operating intervals can be achieved.

These results are summarized in figures 13 and 14 . They show the number of operating intervals and the heat pump work for one month for different tested volumes. The reference volume (750 l) is set to $100 \%$ in each chart and represents the volume of a reference field test object's buffer storage. The results show a lower heat pump work using smaller buffer storages, because of storage heat losses being smaller. But a strong increase of operating intervals can be observed, too.

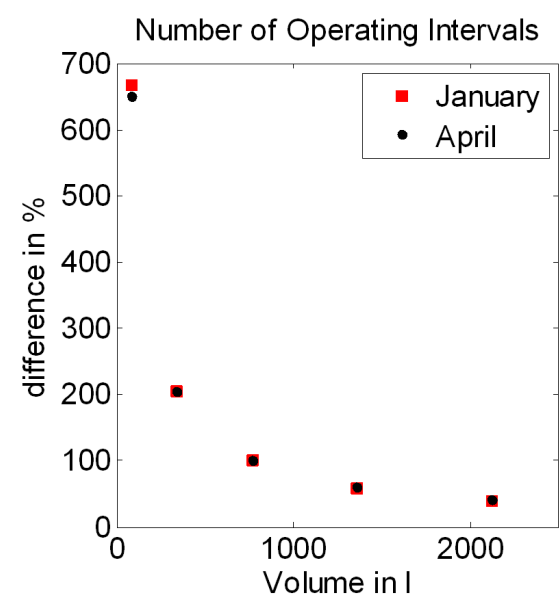

Figure 13: Simulation results: Heat pump working intervals (four week simulation each).

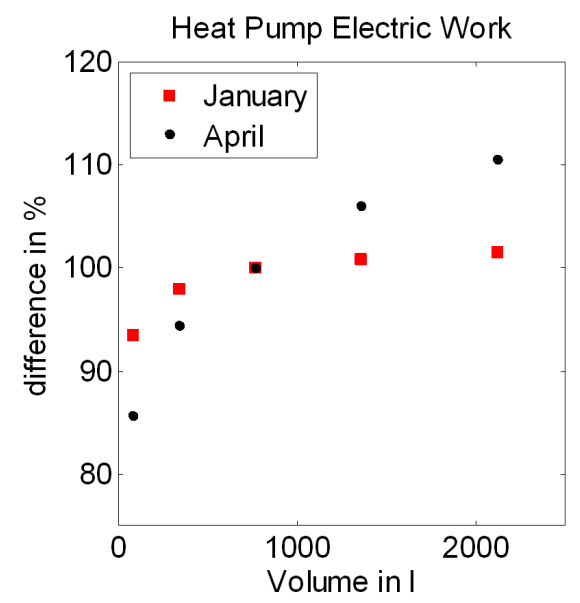

Figure 14: Simulation results: Heat pump electric work (four week simulation each).

\section{Summary and Outlook}

The system models regarded in this paper describe the heat source, the heat pump system including valves, storages and controls and the building as heat sink, including the building envelope, air volume and user influences. Analyses are made to detect possible enhancements for heat pump systems. The focus lies on the analyses of different system arrangements and control strategies.

The presented libraries and components allow a detailed energetic modeling and simulation of single and multi-family houses. User defined buildings and building services installations can be modeled taking into account the diversity of such systems in reality.

The heat pump system library is currently being extended by more detailed models. A detailed heat pump model will describe the heat pump refrigerant circuit. 
The ground source heat exchanger models will be enhanced, allowing the simulation of ground source heat exchanger fields and of ground-water flow.

\section{Acknowledgement}

The authors would like to thank the E.ON gGmbH for the project's promotion. Thanks are also given to E.ON Energie and the Fraunhofer Institute for Solar Energy Systems for cooperation and transmission of field test data.

\section{References}

[1] VDI-Richtlinie 4650: Calculation of heat pumps - simplified method for the calculation of the seasonal performance factor of heat pumps. Verein Deutscher Ingenieure, Düsseldorf, 2009.

[2] A. Hoh, T. Haase, T. Tschirner, D. Müller. A combined thermo-hydraulic approach to simulation of active building components applying Modelica. In Proc. of 4th International Modelica Conference, Hamburg, March 2005.

[3] DIN EN 255-3 Luftkonditionierer, Flüssigkeitskühlsätze und Wärmepumpen mit elektrisch angetriebenen Verdichtern - Heizen. Deutsches Institut für Normung e.V., Berlin, 2007.

[4] F. Casella, C.Richter. ExternalMedia: A Library for Easy Re-Use of External Fluid Property Code in Modelica. In Proc. of 6th International Modelica Conference, pages 157-161, Bielefeld, March 2008.

[5] C. Clauser Numerical Simulation of Reactive Flow in Hot Aquifers Using Shemat/Processing Shemat. Berlin, Heidelberg, Springer Publishing, 2003.

[6] Viskanta et al. Interferometric Observations of the Temperature Structure in Water Cooled or Heated from Above, Advances in Water Resources, Vol. 1, No. 2, 1977 